\title{
Puberdade precoce e as consequências emocionais no desenvolvimento infantil
}

\author{
Early puberty and the psychological effects on child development \\ Pubertad precoz y efectos psicológicos en el desarrollo infantil
}

\begin{abstract}
Paola Cristine de Souza Medeiros ${ }^{1 *}$, Arthur Cardoso Moreno ${ }^{1}$, Juliana Amorim Alfaix Natário1, Larissa de Farias Teixeira1, Maria Antônia Morais de Meloํ․, Maria Laura Thomaz Rossi Romani ${ }^{1}$, Raiane Caroline Paiva de Farias ${ }^{1}$, Vitor Pereira Santana ${ }^{1}$, Thainá Sambiazi Napoleão ${ }^{1}$, Andressa Massarenti Lopes².
\end{abstract}

\section{RESUMO}

Objetivo: Reconhecer as consequências emocionais da puberdade precoce no desenvolvimento das crianças, visando uma atualização desta condição clínica de grande importância para a Endocrinologia Pediátrica e Psiquiatria infantojuvenil. Métodos: Foi feita uma revisão integrativa da literatura através das palavras-chave "puberdade precoce", "crianças" e "desenvolvimento infantil" nas principais bases de dados eletrônicas: LILACS, Scielo e PubMed. Resultados: Foram encontradas 132 publicações científicas de acordo com a seguinte questão norteadora: além das repercussões físicas, existem consequências emocionais no desenvolvimento de crianças acometidas pela puberdade precoce? Destas, 14 cumpriam com os critérios de inclusão e 118 publicações não cumpriam com os critérios de inclusão e foram descartadas. Considerações finais: A puberdade precoce está associada ao desenvolvimento de transtornos de ansiedade e/ou depressão e por isso é fundamental que os pais procurem ajuda médica especializada em casos de suspeita e/ou aparecimento de sinais clínicos. Sendo assim, o tratamento deve ser instituído quando necessário visto que pode ter ação benéfica no atraso do desenvolvimento de características sexuais secundárias e também na prevenção de problemas emocionais.

Palavras-chave: Puberdade precoce, Crianças, Desenvolvimento infantil.

\begin{abstract}
Objective: Recognize the emotional consequences of early puberty on children's development, aiming to update this clinical condition of great importance for Pediatric Endocrinology and Child and Adolescent Psychiatry. Methods: An integrative literature review was carried out using the keywords "precocious puberty", "child development", "children" and "emotional consequences" in the main electronic databases: LILACS, Scielo and PubMed. Results: 132 scientific publications were found according to the following guiding question: in addition to the physical repercussions, are there emotional consequences for the development of children affected by precocious puberty? Of these, 14 met the inclusion criteria and 118 publications did not meet the inclusion criteria and were discarded. Final considerations: Early puberty is associated with the development of anxiety and / or depression disorders and it is therefore essential that parents seek specialized medical help in cases of suspicion and / or the appearance of clinical signs. Therefore, treatment should be instituted when necessary since it can have a beneficial action in delaying the development of secondary sexual characteristics and also in preventing emotional problems.
\end{abstract}

Keywords: Early puberty, Children, Child development.

${ }_{1}^{1}$ Faculdade Ceres (FACERES), São José do Rio Preto - SP. *E-mail: paolamedeiros1804@gmail.com

2 Hospital Carlos Fernando Malzoni, Matão - SP. 


\section{RESUMEN}

Objetivo: Reconocer las consecuencias emocionales de la pubertad precoz en el desarrollo infantil, con el objetivo de actualizar esta condición clínica de gran importancia para la Endocrinología Pediátrica y la Psiquiatría Infantil y Juvenil. Métodos: Se realizó una revisión integradora de la literatura utilizando las palabras clave "pubertad precoz", "desarrollo infantil", "niños" y "consecuencias emocionales" en las principales bases de datos electrónicas: LILACS, Scielo y PubMed. Resultados: Se encontraron 132 publicaciones científicas según la siguiente pregunta orientadora: además de las repercusiones físicas, ¿existen consecuencias emocionales para el desarrollo de los niños afectados por la pubertad precoz? De estos, 14 cumplieron con los criterios de inclusión y 118 publicaciones no cumplieron con los criterios de inclusión y fueron descartadas. Consideraciones finales: La pubertad precoz se asocia al desarrollo de trastornos de ansiedad y / o depresión, por lo que es fundamental que los padres busquen ayuda médica especializada en casos de sospecha y / o aparición de signos clínicos. Por lo tanto, el tratamiento debe instituirse cuando sea necesario, ya que puede tener una acción beneficiosa para retrasar el desarrollo de características sexuales secundarias y también para prevenir problemas emocionales.

Palabras- clave: Pubertad precoz, Niños, Desarrollo infantil.

\section{INTRODUÇÃO}

A puberdade é descrita como o início da adolescência e caracteriza-se por um período fisiológico da vida em que a criança, devido à atividade gonadal, desenvolve características sexuais secundárias e adquire a capacidade de reprodução. Com exceção do período intrauterino, nenhuma outra fase do desenvolvimento apresenta crescimento em altura e mudanças corpóreas de forma tão rápida e intensa como na fase da puberdade. $O$ estirão puberal tem duração de aproximadamente 3 a 4 anos e representa ganho de cerca de $20 \%$ da estatura e $50 \%$ do peso na fase adulta do indivíduo. (CHIPKEVITCH E, 2001).

A idade cronológica durante a adolescência deixa de ser um parâmetro seguro para a caracterização biopsicossocial do indivíduo. A justificativa para tal constatação é de que adolescentes de mesma idade freqüentemente podem estar em fases distintas da puberdade, visto que o início e ritmo de progressão são muito variáveis entre eles. Por isso, a maioria dos eventos puberais, a presença de patologias associadas à puberdade e algumas dosagens laboratoriais se correlacionam mais com determinadas fases da puberdade do que com a idade cronológica (CHIPKEVITCH E, 2001).

As mudanças corporais presentes durante a transição da infância para adolescência demonstram impacto psicológico significativo na época da puberdade. A partir das transformações físicas acontecerão mudanças a nível das emoções, sensações e afetos, visto que as próprias alterações hormonais modificam as sensações corporais do púbere. O humor e comportamento nessa faixa etária são muitas vezes considerados instáveis, imprevisíveis e contraditórios. Tal comportamento pode ser caracterizado pela busca do autoconhecimento e da independência, pontos importantes para a formação da identidade (ABREU DP, 2004). Esses atributos comportamentais também são acompanhados por algumas mudanças hormonais e neurobiológicas desencadeadas em regiões específicas do cérebro, como por exemplo no córtex da área pré-frontal (LEE F, et al., 2014).

Fisiologicamente, o início da puberdade é marcado pelo aumento de amplitude e frequência dos pulsos do hormônio secretor de gonadotrofinas $(\mathrm{GnRH})$ após um período de relativa supressão hormonal durante a infância. Consiste em um período de intensas modificações, marcado principalmente por alterações biológicas da puberdade e à maturidade biopsicossocial do indivíduo (MONTE O, et al., 2001).

A puberdade precoce é uma condição patológica e pode ser definida nas meninas quando o desenvolvimento dos caracteres sexuais secundários ocorre antes dos 8 anos de idade e nos meninos antes dos 9 anos de idade. Tal condição pode ocorrer como resultado da secreção de esteroides sexuais independente da ativação do eixo gonadotrófico, denominada puberdade precoce periférica ou por uma ativação prematura do eixo hipotálamo-hipófise-gonadal, denominada puberdade precoce central (MACEDO DB, et al., 2014). 
Na chamada puberdade precoce central ou verdadeira, há um despertar prematuro do eixo hipotálamohipófise-gonadal (HHG), fazendo com que esses hormônios sejam produzidos antes do período natural, provocando o desenvolvimento puberal (ABREU DP, 2004). As principais causas envolvem condições como hamartomas hipotalâmicos, gliomas, astrocitomas, e germinomas, porém, também pode ocorrer em crianças com hidrocefalia ou outras lesões do sistema nervoso central, após um episódio de meningite, decorrente de lesões cerebrais traumáticas ou exposição à radioterapia prévia da cabeça (BESERRA IZR, 2011). Além disso, uma análise de 156 pacientes com puberdade precoce central idiopática indicou uma prevalência de $27,5 \%$ de casos familiares, sugerindo a relevância dos fatores genéticos na patogênese da puberdade precoce (MACEDO DB, et al., 2014).

Diferentemente da puberdade verdadeira, a puberdade precoce periférica ou também denominada pseudopuberdade, não está ligada ao eixo HHG e surge independente da sua maturação, sendo que as características sexuais secundárias aparecem devido à maturação precoce das células secretoras de esteróides, gônadas ou córtico-suprarrenais (ABREU DP, 2004). Pode ocorrer em decorrência de fatores externos como a ingestão terapêutica ou acidental de estrogênios ou androgênios, ou por outras condições que incluem tumores, distúrbios da síntese de esteroides adrenais e, raramente, a síndrome de McCuneAlbright ou a testotoxicose familiar (BESERRA IZR, 2011).

Sem o diagnóstico e intervenção adequada as crianças com puberdade precoce podem estar expostas a inúmeras consequências na vida adulta como transtornos psicossociais, perda progressiva da estatura final, obesidade, síndrome metabólica, hipertensão, diabetes mellitus tipo 2, doenças cardiovasculares, acidente vascular cerebral e câncer de mama (CRISTINA LCC e PUÑALES M, 2016). Além disso, a precocidade desta etapa do desenvolvimento desencadeia na criança sentimentos confusos, já que a mesma não possui ainda recursos cognitivos e emocionais para lidar com todas as mudanças associadas a este período, principalmente alterações na imagem corporal e o comprometimento nas relações sociais (ABREU DP, 2004).

Por se tratar de um fenômeno relativamente frequente nas clínicas médicas infantis, e visto a complexidade de fatores envolvidos, esta patologia necessita de um suporte complexo e multiprofissional envolvendo não só a esfera orgânica, mas também a cognitiva, emocional e social. Sendo assim, o objetivo principal desta revisão é reconhecer as consequências emocionais da puberdade precoce no desenvolvimento infantil, visando uma atualização desta condição clínica de grande relevância para a Endocrinologia Pediátrica e Psiquiatria Infantojuvenil.

\section{MÉTODOS}

O presente estudo se caracteriza como uma revisão integrativa da literatura. Em função da quantidade crescente das informações na área da saúde, tornou-se imprescindível desenvolver na pesquisa científica outras metodologias que fossem capazes de oferecer aos profissionais um melhor aproveitamento das evidências oriundas de diversos estudos através de etapas mais concisas. Nesse cenário, a revisão integrativa é a metodologia que fornece síntese do conhecimento e aplicabilidade dos resultados de estudos significativos na prática, já que permite a inclusão de estudos experimentais e não-experimentais, além de incorporar inúmeros propósitos em torno de um tópico particular ou de uma questão norteadora (WHITTEMORE R E KNAFL K, 2005).

As seis fases de elaboração da revisão integrativa incluem a 1) identificação do tema e definição da questão norteadora, 2) estabelecimento dos critérios de inclusão e exclusão, 3) definição das bases eletrônicas para coleta de dados, 4) avaliação dos estudos encontrados, 5) apresentação dos resultados e 6) discussão (SOUZA MT, et al., 2010).

Para a elaboração do presente estudo, foi realizada uma busca eletrônica nas bases de dados LILACS, Scielo e PubMed, sendo que os títulos e os resumos de todos as produções encontradas foram revisados integralmente para que com base nos critérios de inclusão fossem selecionadas.

A coleta de dados ocorreu a partir do mês de novembro de 2020 e se estendeu até março de 2021, a partir da palavra-chave puberdade precoce em associação a outros descritores, como "puberdade precoce", "crianças" e "desenvolvimento infantil" na língua portuguesa, assim como seus correspondentes na língua inglesa. 
Como critérios de inclusão foram utilizados: artigos de pesquisa, relatos de caso, ensaios e revisões de literatura em periódicos de língua portuguesa e inglesa publicados a partir de 2015 que se relacionavam com a temática. Não cumpriam com os critérios de inclusão os estudos que foram publicados há mais de cinco anos e que não traziam nenhuma abordagem dos aspectos psicológicos no desenvolvimento das crianças com puberdade precoce, sendo então, excluídos desta revisão.

Esse método de pesquisa organiza, critica e integra as evidências disponíveis publicadas na área da saúde através da busca de produções científicas na literatura. Ele determina o conhecimento atual sobre uma temática específica, já que é conduzida de modo a identificar, analisar e sintetizar resultados de estudos independentes sobre o mesmo assunto.

\section{RESULTADOS}

Inicialmente a seguinte questão norteadora foi definida: além das repercussões físicas, existem consequências emocionais no desenvolvimento de crianças acometidas pela puberdade precoce? Se sim, quais são elas?

Esse método de pesquisa organiza é conduzido de modo a identificar, analisar e sintetizar resultados de estudos independentes sobre o mesmo assunto. Foram então encontradas nas plataformas digitais 132 publicações científicas, sendo que 14 cumpriam com os critérios de inclusão e foram consideradas potencialmente relevantes para serem utilizadas nesta revisão (Quadro 1). Dentre elas, 10 estavam disponíveis no PubMed, 3 no Scielo e 1 na Lilacs. As outras 118 publicações não cumpriam com os critérios de inclusão e foram descartadas (Figura 1). Dentre as 14 publicações científicas selecionadas, apenas uma foi escrita na língua portuguesa e publicada em periódico nacional.

Figura 1 - Esquema representativo das etapas da busca eletrônica.

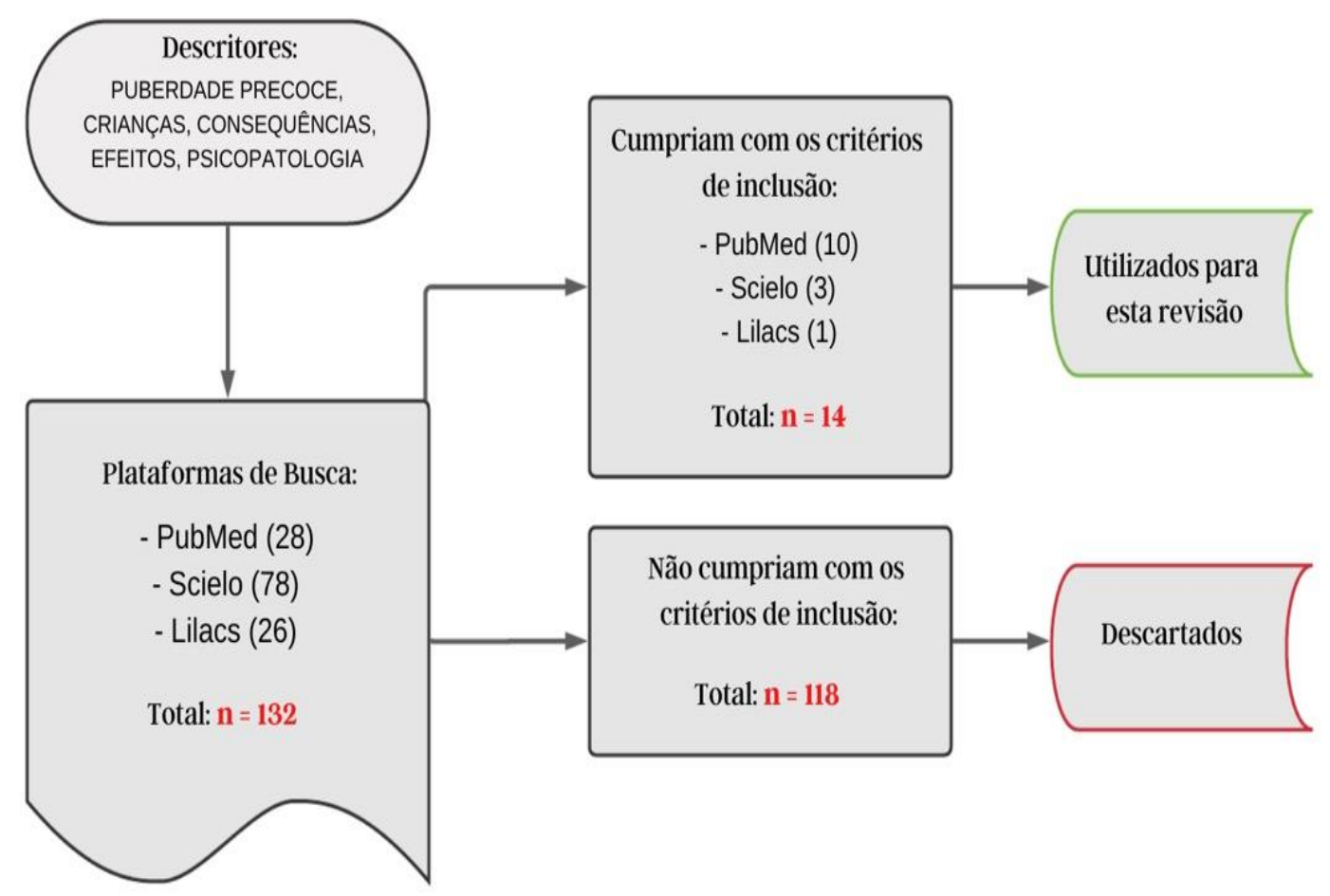

Fonte: Medeiros PCS, et al., 2021. 
Quadro 1 - Artigos selecionados pelos critérios de inclusão.

\begin{tabular}{|c|c|c|c|}
\hline Artigos & Autor/ano & Objetivo & Resultados \\
\hline $\begin{array}{l}\text { Psychological assessment of mothers and their } \\
\text { daughters at the time of diagnosis of precocious } \\
\text { puberty }\end{array}$ & $\begin{array}{l}\text { SCHOELWER MJ, et al., } \\
\qquad 2015\end{array}$ & $\begin{array}{l}\text { Comparar o sofrimento e estresse em meninas } \\
\text { com e sem puberdade precoce }\end{array}$ & $\begin{array}{l}\text { Meninas com puberdade precoce são mais propensas a sofrerem } \\
\text { constrangimento e isolamento social }\end{array}$ \\
\hline $\begin{array}{l}\text { Early Life Stress Delays Sexual Maturation in } \\
\text { Female Mice }\end{array}$ & NIEVES GM, et al., 2019 & $\begin{array}{l}\text { Avaliar se o estresse no início da vida afetou } \\
\text { momento de maturação sexual em camundongos } \\
\text { fêmeas }\end{array}$ & $\begin{array}{l}\text { O estresse no início da vida impactou nas medidas dos ciclos de } \\
\text { estrogênio }\end{array}$ \\
\hline $\begin{array}{l}\text { Effects of early menarche on physical and } \\
\text { psychosocial health problems in adolescent girls } \\
\text { and adult women }\end{array}$ & YOO JH, 2016 & $\begin{array}{l}\text { Revisar os problemas de saúde física e } \\
\text { psicossocial que podem ocorrer na vida das } \\
\text { mulheres devido à puberdade precoce }\end{array}$ & $\begin{array}{l}\text { Os estudos descrevem a associação entre os problemas } \\
\text { psicossociais ao longo de toda a vida das mulheres que tiveram } \\
\text { puberdade precoce }\end{array}$ \\
\hline $\begin{array}{l}\text { Increased symptoms of anxiety and depression in } \\
\text { prepubertal girls, but not boys, with premature } \\
\text { adrenarche: associations with serum DHEAS and } \\
\text { daily salivary cortisol concentrations }\end{array}$ & MARAKAKI C, et al., 2018 & $\begin{array}{l}\text { Examinar os perfis psicológicos de meninas e } \\
\text { meninos com puberdade precoce no momento } \\
\text { do diagnóstico }\end{array}$ & $\begin{array}{l}\text { Meninas com puberdade precoce estão em maior risco de } \\
\text { sintomas de ansiedade e depressão }\end{array}$ \\
\hline $\begin{array}{l}\text { Advanced bone age as an indicator facilitates the } \\
\text { diagnosis of precocious puberty }\end{array}$ & XU YQ, et al., 2018 & $\begin{array}{l}\text { Encontrar um indicador que dá estimulação do } \\
\text { GNRH em indivíduos com puberdade precoce }\end{array}$ & $\begin{array}{l}\text { Idade óssea avançada é o preditor mais eficaz do teste de } \\
\text { estimularão do GNRH }\end{array}$ \\
\hline $\begin{array}{l}\text { Puberdade em uma amostra de meninos } \\
\text { escolares brasileiros: início e características } \\
\text { antropométricas }\end{array}$ & FEIBELMANN, et al., 2019 & $\begin{array}{l}\text { Determinar a idade em que a puberdade precoce } \\
\text { começa em meninos e coletar os dados } \\
\text { antropométricos }\end{array}$ & Há uma tendência secular em direção à diminuição da pubarca \\
\hline $\begin{array}{l}\text { Hidden by the air - a precocious puberty case } \\
\text { report }\end{array}$ & FERREIRA FA, et al., 2020 & $\begin{array}{l}\text { Relatar o caso de uma criança do sexo feminino } \\
\text { com pubarca precoce desde os } 6 \text { anos de idade }\end{array}$ & $\begin{array}{l}\text { No caso, a puberdade precoce foi tratada em função das } \\
\text { potenciais consequências psicológicas e na estatura final da } \\
\text { criança }\end{array}$ \\
\hline $\begin{array}{l}\text { Puberty and the human brain: insights into } \\
\text { adolescent development }\end{array}$ & PFEIFER J, et al., 2018 & $\begin{array}{l}\text { Revisar sistematicamente o desenvolvimento } \\
\text { estrutural e funcional do cérebro relacionado à } \\
\text { puberdade em humanos }\end{array}$ & $\begin{array}{l}\text { Estudos são necessários para ajudar a resolver as } \\
\text { inconsistências atuais para compreender de forma mais clara a } \\
\text { associação da puberdade com o desenvolvimento do cérebro em } \\
\text { humanos }\end{array}$ \\
\hline Interviewing adolescents about sexual matters & PFEFFER B, et al., 2017 & $\begin{array}{l}\text { Fornecer sugestões úteis e práticas para iniciar } \\
\text { conversas sobre sexualidade com adolescentes }\end{array}$ & $\begin{array}{l}\text { Pediatras e outros profissionais da saúde podem o reforçar o } \\
\text { desenvolvimento sexual de forma natural e ajudar os } \\
\text { adolescentes a terem um estilo de vida saudável }\end{array}$ \\
\hline $\begin{array}{l}\text { Childhood sexual abuse and early timing of } \\
\text { puberty }\end{array}$ & NOLL JG, et al., 2016 & $\begin{array}{l}\text { Avaliar se o momento da puberdade foi precoce } \\
\text { para meninas abusadas sexualmente em } \\
\text { comparação com um grupo de meninas não } \\
\text { abusadas }\end{array}$ & Abuso sexual teve associação com a puberdade precoce \\
\hline $\begin{array}{l}\text { Early puberty is associated with mental health } \\
\text { problems in middle adolescence }\end{array}$ & $\begin{array}{l}\text { MARTTUNEN M, et al., } \\
2015\end{array}$ & $\begin{array}{l}\text { Avaliar a relação entre os problemas emocionais } \\
\text { e de comportamento durante a puberdade }\end{array}$ & $\begin{array}{l}\text { Em meninos e meninas, os problemas foram comuns quando a } \\
\text { puberdade ocorreu de forma precoce }\end{array}$ \\
\hline $\begin{array}{l}\text { Is obesity at individual and national level } \\
\text { associated with lower age at menarche? }\end{array}$ & CURRIE C, et al, 2016 & $\begin{array}{l}\text { Investigar a contribuição do IMC para a menarca } \\
\text { em nível individual e nacional }\end{array}$ & $\begin{array}{l}\text { A obesidade infantil é um fator de risco para a puberdade } \\
\text { precoce, principalmente em meninas }\end{array}$ \\
\hline $\begin{array}{l}\text { Central precocious puberty: revisiting the } \\
\text { diagnosis and therapeutic management }\end{array}$ & BRITO VN, et al, 2016 & $\begin{array}{l}\text { Revisar as características diagnósticas e } \\
\text { terapêuticas da puberdade precoce central }\end{array}$ & $\begin{array}{l}\text { Puberdade é um processo multifatorial e o diagnóstico clínico } \\
\text { nem sempre é fácil }\end{array}$ \\
\hline $\begin{array}{l}\text { Early Puberty and Childhood Social and } \\
\text { Behavioral Adjustment }\end{array}$ & MENSAH FK, et al., 2018 & $\begin{array}{l}\text { Determinar se as dificuldades no comportamento } \\
\text { psicossocial são evidentes antes e durante a } \\
\text { puberdade }\end{array}$ & $\begin{array}{l}\text { Crianças com puberdade precoce têm diferentes padrões de } \\
\text { comportamento desde os anos antes do início da adolescência }\end{array}$ \\
\hline
\end{tabular}

Fonte: Medeiros PCS, et al., 2021. 


\section{DISCUSSÃO}

Visto que a puberdade é um período marcado pela liberação de diversos hormônios que desencadeiam o processo de maturação sexual na criança, pode-se esperar como resultado não só as mudanças físicas e biológicas, mas também mudanças extremamente marcantes nos processos sociais, emocionais e cognitivos (PFEIFER JH, et al., 2018).

Geralmente idiopática, a puberdade precoce afeta meninas antes dos oito anos e meninos antes dos nove anos de idade, gerando repercussões secundárias como crescimento precoce de pelos pubianos, redução da estatura, desenvolvimento prematuro das mamas e outros impactos como o estresse psicológico ( $\mathrm{XU} Y \mathrm{Y}-\mathrm{Q}$, et al., 2018). Um estudo populacional na Dinamarca evidenciou que a incidência da puberdade precoce é de 20 casos a cada 10.000 meninas e de 5 casos a cada 10.000 meninos, uma frequência quatro vezes maior no sexo feminino que no masculino (TEILMANN G, et al., 2005).

Apesar da etiologia multifatorial, acredita-se que exista uma forte associação entre a obesidade infantil e o desenvolvimento puberal antecipado, uma vez que os maiores níveis de leptina na obesidade têm papel permissivo sobre a secreção de GnRH em nível hipotalâmico. Sendo assim, com o aumento significativo do número de crianças com sobrepeso nas últimas décadas, a tendência é que a quantidade de casos de puberdade precoce também aumente com o passar dos anos (CURRIE C, et al., 2016).

Outra pesquisa, realizada nos Estados Unidos no ano de 2016, utilizou dados internacionais padronizados exclusivos de meninas adolescentes em 34 países da Europa e América do Norte que participaram de um estudo de comportamento de saúde em crianças em idade escolar, também evidenciou que a obesidade na infância é um fator de risco para a puberdade precoce em meninas e é responsável por grande parte da variação entre os países na idade da menarca (CURRIE C, et al., 2016).

Nas meninas, o primeiro sinal de puberdade precoce é geralmente o aumento das mamas, que pode inicialmente ser unilateral. Os pelos pubianos e axilares podem aparecer antes, quase ao mesmo tempo ou bem depois do aparecimento do tecido mamário e a menarca é um evento mais tardio que não costuma ocorrer até 2-3 anos após o início do aumento das mamas (KAPLOWITZ PB, 2020).

Já nos meninos, a primeira evidência da puberdade precoce é o aumento dos testículos, um achado sútil que muitas vezes passa despercebido pelos pacientes e familiares. $O$ crescimento do pênis e do escroto normalmente ocorre pelo menos um ano após o aumento testicular e o crescimento linear acelerado ocorre mais tarde no curso da puberdade masculina do que na puberdade feminina (KAPLOWITZ PB, 2020).

O desenvolvimento de alterações físicas possivelmente gera repercussões emocionais em crianças acometidas pelo início precoce da puberdade, visto que muitas vezes as mudanças corpóreas são perceptíveis e resultam em distúrbios psicossociais. Inclusive, alguns estudos evidenciam que o aparecimento precoce de seios ou menstruação em meninas, assim como o aumento da libido em meninos podem causar desgaste emocional em algumas crianças (KAPLOWITZ PB, 2020).

Sendo assim, a puberdade de forma prematura afeta não só a criança, mas também os seus familiares que se demonstram angustiados diante do desenvolvimento físico de seus filhos, sendo a incompatibilidade entre a idade e o desenvolvimento físico um fator determinante para as vivências sociais infantis e familiares (SCHOELWER M, et al., 2015).

Um estudo conduzido na Universidade de Medicina de Indiana, nos Estados Unidos, recrutou meninas que foram diagnosticadas com puberdade precoce juntamente com suas mães. Enquanto as garotas completaram um questionário de depressão infantil e uma escala de percepção e aceitação social para jovens, as mães preencheram outro questionário que avaliava os níveis de ansiedade e estresse. Os resultados indicaram que as meninas com puberdade em início precoce eram propensas a sofrer constrangimentos sociais e sofriam com a aparência, diferente das demais meninas da mesma idade, e que as mães apresentaram níveis de depressão e estresse aumentados, além de relatarem se sentirem preocupadas com as mudanças físicas corporais, com a rejeição e com os comportamentos sexuais de suas filhas (SCHOELWER MJ, et al., 2015). 
Um outro estudo realizado pela Duke University e University of California evidenciou que crianças que passam por esse processo puberal são mais propensas a apresentar act-out (termo da psicologia no qual a pessoa ao invés de expressar seus sentimentos com palavras, faz algum ato extremo, como socar a parede) e sofrer de ansiedade e depressão (MARAKAKI C, et al., 2018). O que demostra que o início da puberdade mais precocemente, realmente pode ser associado a uma maior chance de desenvolvimento de transtornos emocionais e comportamentais.

É válido lembrar também que o desenvolvimento precoce pode levar ao início da vida sexual de forma antecipada, provocando comportamentos sexuais de risco, culminando em alguns casos em doenças sexualmente transmissíveis e gestações indesejadas, como foi observado em um estudo com adolescentes coreanos. Além disso, o uso de cigarros, álcool e maconha foi mais prevalente nestes adolescentes do que naqueles que tiveram o início da puberdade na idade adequada (YOO J, 2016).

Da mesma forma, uma pesquisa realizada em diversas escolas de 13 cidades da Finlândia que incluía perguntas sobre depressão, bulimia nervosa, sintomas psicossomáticos, ansiedade, bebidas, uso de substâncias ilícitas, fumo, bullying e transgressão concluiu que o início da maturidade precoce está associado ao aumento dos problemas de saúde mental (MARTTUNEN M, et al., 2015).

A sexualidade que acompanha a adolescência representa um desafio para os jovens, pois os mesmos precisam se adequar ao funcionamento de um corpo em maturação sexual, além de terem que lidar com o surgimento de desejos sexuais. Por isso, o desenvolvimento de uma sexualidade saudável deve fazer parte do acompanhamento físico e emocional das crianças, sobretudo das que iniciam ainda mais precocemente a puberdade (PFEFFER B, et al., 2016).

A maioria dos casos de puberdade precoce é diagnosticado apenas por meio da avaliação dos sinais e sintomas apresentados pela criança. No entanto, no caso de suspeita de alteração grave ou presença de síndrome, o médico pode recomendar a realização de exames complementares como Raio-X, ultrassom da pelve e das suprarrenais, tomografia computadorizada ou ressonância magnética, por exemplo (BRITO VN, et al., 2016).

Além dos exames complementares, o estadiamento puberal permite ao profissional médico compreender o momento maturacional do adolescente, podendo oferecer ao jovem, orientação antecipada sobre os próximos eventos da puberdade e tratar patologias associadas à puberdade. Alguns modelos de estadiamento puberal foram propostos nas décadas de 1940 e 1950, porém, o médico inglês J.M. Tanner padronizou um método de estadiamento da maturação sexual, que se difundiu a partir dos anos 1960 e é o mais utilizado até os dias de hoje. Através da avaliação das mamas $(M)$ e dos pêlos pubianos $(P)$ nas meninas, e dos genitais $(G)$ e pêlos pubianos $(P)$ nos meninos, pode-se classificar os estágios de Tanner em cinco. $O$ estágio 1 corresponde à fase infantil, (impúbere) e o estágio 5 à fase pós-puberal (adulta). Portanto, são os estágios 2, 3 e 4 que caracterizam o período puberal (CHIPKEVITCH E, 2001).

Dessa maneira, o diagnóstico pode ser esclarecido e o tratamento instituído quando necessário visto que sua abordagem precoce pode ter ação benéfica na fertilidade e na redução do risco de câncer de mama associado à menarca precoce nas meninas, além de diminuir o grau de ansiedade na criança e nos familiares e evitar o risco de abuso sexual a que tais crianças estão susceptíveis. (MONTE O, et al., 2001).

Para indicar o tratamento, não deve se levar em consideração somente a idade de início dos sinais puberais, mas também a velocidade de progressão, uma vez que um desenvolvimento acelerado pode apresentar maior risco de prejuízo à estatura final. $O$ tratamento na puberdade precoce verdadeira tem como objetivo cessar o processo de amadurecimento prematuro até que a criança já tenha adquirido estatura adequada e amadurecimento psicológico e social para começar o processo de puberdade espontâneo (ABREU DP, 2004).

Estudos demonstram que meninas menores de 6 anos parecem ser o grupo que mais se beneficia desse tratamento, com ganho estatural de cerca de 9 a $10 \mathrm{~cm}$. Para meninos esse benefício ainda não está claramente demonstrado (BRITO VN, et al., 2016). 
A abordagem terapêutica pode ser realizada através de drogas supressoras do eixo HHG, inibindo a secreção de hormônios que estimulam os ovários, bloqueando os caracteres sexuais secundários e mesmo provocando sua regressão temporária a fim de evitar o amadurecimento ósseo acelerado. A monitorização do tratamento deve ser feita a partir de consultas clínicas periódicas com avaliação do estágio puberal, do crescimento linear e da tolerância ou efeitos adversos do tratamento preferencialmente a cada 3 meses (ABREU DP, 2004).

No caso da pseudopuberdade precoce, ao contrário da puberdade precoce verdadeira, o tratamento farmacológico não é necessário. Quando a causa é idiopática os caracteres regridem espontaneamente, porém, ainda se faz necessário o apoio psicológico, visto que a criança também sofre alterações corporais, embora temporárias (ABREU DP, 2004).

Pode se dizer que a puberdade marca um ponto de transição na saúde mental das crianças com mudanças nas taxas de prevalência de transtornos mentais e comportamentais após a transição puberal. Existem várias razões pelas quais a puberdade precoce pode aumentar a vulnerabilidade a problemas de saúde mental na adolescência, mas todas vão ao encontro da teoria de incompatibilidade entre os desafios emocionais e as capacidades cognitivas de jovens adolescentes (MENSAH FK, et al., 2018).

Portanto, compreender os fatores ambientais que impactam no momento da maturação sexual é importante não somente para implementar estratégias de intervenção, mas também para instituir políticas públicas de prevenção. Diversas teorias demonstram que altos níveis de estresse precoce durante a vida aceleram o processo de maturação sexual, sendo assim, é necessário compreender os mecanismos que apoiam as mudanças no desenvolvimento sexual e como esses fatores podem impactar os resultados neurocomportamentais (NIEVES GM, et al., 2019).

\section{CONSIDERAÇÕES FINAIS}

Conforme foi discutido, o desenvolvimento precoce da puberdade em crianças está associado aos transtornos de ansiedade, depressão e uso de substâncias ilícitas. Além disso, essa condição pode levar ao início da vida sexual de forma antecipada, o que pode culminar em doenças sexualmente transmissíveis e gestações indesejadas. Por se tratar de uma condição com repercussões a curto, médio e longo prazo no estado de saúde da criança, é de fundamental importância o planejamento e a implementação de ações de promoção à saúde voltadas para as crianças com puberdade precoce. Dessa forma, além da investigação minuciosa e instituição de tratamento medicamentoso em alguns casos, uma abordagem médica especializada aliada ao apoio e participação familiar são de extrema importância sempre que forem identificadas características clínicas sugestivas de antecipação do desenvolvimento puberal.

\section{REFERÊNCIAS}

1. BRITO VN, et al. Central precocious puberty: revisiting the diagnosis and therapeutic management. Arch Endocrinol Metab, 2016; 60(2): 163-72.

2. CHIPKEVITCH E. Avaliação clínica da maturação sexual na adolescência. Rio de Janeiro. Jornal de Pediatria, 2001; 77(2): 135-142.

3. CHRISANTHI M, et al. Increased symptoms of anxiety and depression in prepubertal girls, but not boys, with premature adrenarche: associations with serum DHEAS and daily salivary cortisol concentrations. Netherlands. Amsterdam. Stress, 2018; 21(6):564-568.

4. CURRIE C, et al. Is obesity at individual and national level associated with lower age at menarche? Evidence from 34 countries in the Health Behaviour in School-aged Children Study. J Adolesc Health, 2016; 50(6): 621-6.

5. LEE F, et al. Adolescent mental health - opportunity and obligation. Science Mental Health, 2014; 346: 547-549.

6. MACEDO DB, et al. Avanços na etiologia, no diagnóstico e no tratamento da puberdade precoce central. São Paulo. Arquivo Brasileiro de Endocrinologia e Metabologia, 2014; 58(2):108-117.

7. MANZANO NG, et al. Early Life Stress Delays Sexual Maturation in Female Mice. Frontiers in molecular neuroscience, 2019; $12: 27$.

8. MARTTUNEN M, et al. Early puberty is associated with menta Ihealth problems in middle adolescence. Social Science \& Medicine, 2015; 57: 1055-1064.

9. MEDSCAPE. 2020. In: Pediatrics: Precocious Puberty. Disponível em: https://emedicine.medscape.com/article/924002-overview\#a3. Acesso em: 24 mar. 2021. 
10. MELISSA JS, et al. Psychological assessment of mothers and their daughters at the time of diagnosis of precocious puberty. International Journal of Pediatric Endocrinology, 2015; 2015(1):5.

11. MENSAH FK, et al. Early Puberty and Childhood Social and Behavioral Adjustment. Journal of Adolescent Health, 2018; 53(1): 118-124.

12. MONTE O, et al. Puberdade precoce: dilemas no diagnóstico e tratamento. São Paulo. Arquivo Brasileiro de Endocrinologia e Metabologia, 2001; 45(4):321-330.

13. NOLL JG, et al. Childhood Sexual Abuse and Early Timing of Puberty. Journal of Adolescent Health, 2017; 60(1): 657.

14. PFEFFER B, et al. Interviewing Adolescents About Sexual Matters. Pediatr Clin North Am, 2017;64(2): $291-304$.

15. PFEIFER JH, et al. Puberty and the human brain: insights into adolescent development. Neurosci Biobehav Rev, 2018; 92: 417-436.

16. SCHOELWER, et al. Psychological assessment of mothers and their daughters at the time of diagnosis of precocious puberty. USA. International Journal of Pediatric Endocrinology, 2015; 2015(5).

17. SOCIEDADE BRASILEIRA DE PEDIATRIA. Departamento Científico de Endocrinologia. Puberdade Precoce. 2016. Disponível em: https://www.sbp.com.br/fileadmin/user_upload/2016/09/Puberdade-Precoce.Leila_.Ve4_.pdf. Acesso em: 17 mar. 2021.

18. SOUZA MT, et al. Revisão integrativa: o que é e como fazer. São Paulo, Einstein, 2010; 8(1):102-106.

19. TEILMANN G, et al. Prevalence and incidence of precocious pubertal development in Denmark: an epidemiologic study based on national registries. Pediatrics. 2005;116(6):1323-8.

20. WOJNIUSZ S, et al. Cognitive, Emotional, and Psychosocial Functioning of Girls Treated with Pharmacological Puberty Blockage for Idiopathic Central Precocious Puberty. Frontiers in Psychology, 2016; 7:1053.

21. XU YQ, et al. Advanced bone age as an indicator facilitates the diagnosis of precocious puberty. Journal Pediatrics, 2018; 94:69: 75.

22. YOO J. Effects of early menarche on physical and psychosocial health problems in adolescent girls and adult women. Korea. Korean J Pediatr. 2016; 59(9): 355-36. 